\title{
Factors Associated With Patient Satisfaction - Evidence From A Primary Care Not For Profit Organization In Karachi, Pakistan
}

\author{
Sadia Siddiqi, Faridah Amin, Farheen Saboor
}

$----------------------------------$

ABSTRACT:

Objective: This study was aimed to determine patient satisfaction and factors associated with patient satisfaction in a not for profit private primary healthcare service in Karachi, Pakistan.

Methodology: A cross sectional survey was conducted across eight primary healthcare clinics of Sina Health, Education and Welfare trust. A total of 557 patients visiting these primary healthcare services participated in the study. The questionnaire gauged information in 2 parts: assessing demographics and patient satisfaction with services Chi square use as the test of significance. The data was analyzed on SPSS version 20.

Results: Results revealed that majority (89\%) of the patients were women and more than half were between 30-60 years of age. In the multivariable model, patients were more likely to be satisfied with less waiting time at pharmacy (p 0.007), listening (p 0.01), assessing (p 0.001) and counseling (p 0.007 ) skills of the doctor.

Conclusion: The study highlights a successful possibility of provision of quality primary healthcare services in developing countries with easy access for the people most deserving it especially women, at an affordable cost. One of the unique reasons for satisfaction is the training of Sina doctors and staff on regular basis.

Key Words:: Affordable cost, Counselling, Marginalized, Patient satisfaction, Primary healthcare

\section{INTRODUCTION:}

Access to basic healthcare has long been declared as a fundamental human right ${ }^{1}$. This involves low cost communitybased preventive and curative services, with substantial community involvement. For countries with resource constraints, this has been shown to be the way forward. However, in most developing countries expensive specialistbased health services are frequently used, hence abusing this fundamental right ${ }^{2}$. Most affected are the poor and vulnerable segments of population, for whom, most of the health expenditure is borne out of their pockets ${ }^{3}$ both in terms of access and cost of care.

Pakistan also has a parallel health system comprising both public and private health facilities. The public health care comprises of primary, secondary and tertiary level of care, free of cost. However the population growth has been unmatched, creating a demand supply gap. This is reflected by the presence of the current ratio of one doctor for 1099 persons, 13,441 persons per dentist and availability of one

Sadia Siddiqi

Family Physician and Advisor Clinical Affairs

- Sina Health Education and Welfare Trust

I Karachi

I Faridah Amin

I Asst.Professor Family Medicine

Liaquat National Hospital and Medical College

I National Stadium Road, Karachi

I

Farheen Saboor

I Family Physician

I Liaquat National Hospital and Medical College

National Stadium Road, Karachi

I Email: dr.farheen30@gmail.com

Received: 24-09-18

I Accepted: 27-11-18

Accepted. $27-11-18-1$ hospital bed for 1647 persons ${ }^{4}$. This unmet need is met by the private health facilities, using a fee for service system. In fact, this largely unregulated private sector, serves around $70 \%$ of the country's population ${ }^{5}$.

Understanding this need, Sina Health, Education and Welfare trust undertook this task of setting up primary healthcare (PHC) clinics in the heart of deserving communities. It is largely based on the principal of accessibility, affordability and quality. Over $80 \%$ of Sina's patients are women and children, with over $70 \%$ being Zakat (welfare fund) eligible, who benefit from quality healthcare provided at their doorstep. Over 300,000 patients visit these clinics annually which is projected to go up to half a million, in the next couple of years. Once the load increases, the element of quality tends to be compromised ${ }^{6}$. Yet, Sina's greatest asset is a quality management system. This system is unique, as it has adapted quality healthcare protocols used in developed healthcare systems for application in low-income settings. Patients are examined by qualified and well-trained physicians whose performance is rigorously monitored, with areas of improvement addressed through a robust Continuing Medical Education (CME) program.

For quality control, patient satisfaction survey is not only an important means to ensure better care for the patients, but also helps identify ways to improve practice. Also, these surveys reduce patient defection from our practice and mitigate negative word of mouth ${ }^{7}$.

Mismatch between patient expectation and the service received is associated with dissatisfaction ${ }^{8}$. Patient satisfaction leads to better compliance to treatment plans and generates better outcomes ${ }^{9}$. Moreover, patients are able to form bonds with health care providers that encourage continuity of care. 
Several hospital based researches are available to assess patient satisfaction with hospital functioning but none of them are conducted in the community to our knowledge, especially when a non-governmental organization or the private sector is providing service. Hence, in order to check the quality of the low cost services provided, Sina undertook the task of conducting patient satisfaction survey across its clinics. The results of this study will help focus on areas where patient satisfaction is lacking so improvements can be made. Besides, it will also help the non-governmental organizations providing affordable health care across developing countries to gain an insight to determinants of patient satisfaction hence translating to ensure quality services at an affordable cost.

\section{METHODOLOGY:}

This is a cross-sectional study in which a total of 557 data were collected across eight PHC clinics of Sina in Karachi, Pakistan in 2015. All patients who visited the PHC over a period of one month were invited to participate.

The questionnaire gauged information in two parts: assessing demographics and patient satisfaction with services (preconsultation, doctor's consultation and post-consultation). The outcome variable (overall satisfaction of the patient with the facility, doctor and service) was assessed through a likert scale with four categories, very satisfied, satisfied, dissatisfied and very dissatisfied.

Frequencies and proportions for categorical and continuous variables (e.g number of visits, waiting time, length of consultation) were computed. Chi-square was used to determine association of each independent factor with the outcome (patient satisfaction). Patient satisfaction was measured on a likert scale having four categories as specified, but for logistic regression, the categories were merged in two, so that satisfied and very satisfied were classified as "satisfied", and dissatisfied and very dissatisfied were classified as "not satisfied". Multivariable logistic regression was used to measure the association of multiple independent variables with binary outcome, with a confidence interval of $95 \%$. Final effect model was be made by multivariable analysis by ENTER method. All the independent variables which were had a significant association with the outcome ( $p<0.05)$ were added one by one. Variables which were insignificant were subsequently eliminated from the final model. Model fit was assessed using Receiver Operating Characteristic curve (ROC curve).

\section{RESULTS:}

Among patients attending PHC, $89 \%$ were females and around $48 \%$ of them were accompanied by an attendant (a family member or a friend). Around $40 \%$ were less than 30 years of age while only $2 \%$ were more than 60 years, rest were between 31-60 years. $82 \%$ were married while rest were single (15\%), widowed or divorced (3\%). $84 \%$ of the patients had visited Sina at least thrice for consultation and $81 \%$ were on Zakat (welfare) accounts. Out of $54 \%$ who were taken to medical treatment room, $24 \%$ were taken for a blood test, while $4.2 \%$ had an ultrasound done. $1.4 \%$ were taken for hydration and $1.2 \%$ for nebulization. Among those taken to treatment room, $71 \%$ rated the skill of person testing as "good". $75 \%$ said that they were explained the reason for medical test/procedure and in $95 \%$ of the cases, the doctor explained it. Among patients getting medications, $93 \%$ said that the dosage of medicine was explained to them. In $73 \%$ of the cases the pharmacist explained it while in $24 \%$ cases doctor explained. $81.4 \%$ said that they walked to the clinic while $16.6 \%$ used public transport. The average walking distance from patient's home to Sina clinic was 22 minutes (mins). Patients' average pre-consultation waiting time was 99 mins and post-doctor's consultation visit was 52 mins.

Table 1 shows the factors associated with patient satisfaction. Overall, $95 \%$ of the patients said that they were satisfied with the services. Majority ( $85 \%$ ) of the patients were follow up patients and $80 \%$ said that Sina was maintaining their personal files which was mostly easy to find. Among patients, $77 \%$ said that they were attending the closest clinic from their residence and these patients were also more likely to be satisfied (p 0.04). Patients were also more likely to be satisfied if there was no waiting at the clinic gate (p 0.01). More than half of the patients mentioned more than 15 minutes waiting at the reception while $3 / 4^{\text {th }}$ had to wait for more than 15 minutes for the doctor. The waiting at pharmacy was relatively less. Yet, half of the patients said that they were generally satisfied with the waiting time while patients who had to wait less at the pharmacy were more likely to be satisfied ( $p$ 0.002). Almost all of them rated the hygiene in the clinic to be good or satisfactory. Majority of the patients were called on their turns and almost all of them found the behavior of the staff good or satisfactory. Majority of the patients also graded the doctors' listening, assessing and counseling skills as "good". Patients who rated the staff's and doctor's attitude as good, were more likely to be generally satisfied with the facility $(\mathrm{p}<0.001)$.

Majority of them said that the length of consultation ranged from more than 5 to more than 15 minutes and $3 / 4^{\text {th }}$ said that they were advised about prevention also. Most of them also said that they were explained about medical tests advised ( $75 \%$ ) and dosage of medications (93\%).

In the multivariable regression model (Table 2), waiting time at pharmacy ( $\mathrm{p} 0.007)$ and listening (p 0.01), assessing (p 0.001) and counseling (p 0.007) skills of doctor were significantly associated with satisfaction from services.

\section{DISCUSSION:}

Recently, there has been a paradigm shift in health care from doctor centered to patient centered approach to improve quality of care. Along with this, other approaches like evidence based medicine, total quality medicine, assessment, 
Factors Associated With Patient Satisfaction - Evidence From A Primary Care Not For Profit Organization In Karachi, Pakistan

accreditation and professional development have gained popularity as means to improve quality ${ }^{10}$. Some of these approaches focus on professional quality, while others serve as external controls on quality. Application of these quality measures has improved the standard of health care service in Sina over the last few years. Therefore, majority of the patients in this survey were satisfied with the care they had received.

The results clearly indicate that the physician's communication skills have the greatest impact on patient satisfaction. The value of empathetic listening to patients has been highlighted in previous studies also ${ }^{11}$. Satisfaction with medical personnel is not only shown to be associated with satisfaction with health care service, but, it is also directly associated with patient compliance ${ }^{12,13}$. Training of communication skills to general practitioners has also been shown to improve patient satisfaction in a randomized controlled trial ${ }^{14}$.

In Sina, there is continuous professional development of doctors through monthly CME sessions, medical audits, assessment through annual OSCEs (objective structured clinical exam) and appraisals. For CMEs, specialists in

\begin{tabular}{|c|c|c|c|c|c|c|c|c|}
\hline \multirow{2}{*}{ Variable } & \multirow{2}{*}{ Categories } & \multicolumn{2}{|c|}{ Dissatisfied } & \multicolumn{2}{|c|}{ Satisfied } & \multicolumn{2}{|c|}{ Total } & \multirow{2}{*}{$\mathrm{p}$ value } \\
\hline & & $\mathrm{N}$ & $\%$ & $\mathrm{~N}$ & $\%$ & $\mathrm{~N}$ & $\%$ & \\
\hline \multirow{2}{*}{$\begin{array}{l}\text { Is this clinic closest to your } \\
\text { home }\end{array}$} & Yes & 15 & 3 & 366 & 73.6 & 381 & 76.7 & \multirow{2}{*}{$0.04 *$} \\
\hline & No & 10 & 2 & 106 & 21.3 & 116 & 23.3 & \\
\hline \multirow{3}{*}{ Waiting at main gate } & No waiting & 0 & 0 & 46 & 9.5 & 46 & 9.5 & \multirow{3}{*}{$0.01 *$} \\
\hline & 5-15 minutes & 9 & 1.9 & 233 & 48 & 242 & 49.9 & \\
\hline & $>15$ minutes & 16 & 3.3 & 181 & 37.3 & 197 & 40.6 & \\
\hline \multirow{3}{*}{$\begin{array}{l}\text { Waiting at Pharmacy for } \\
\text { medicine }\end{array}$} & No waiting & 0 & 0 & 8 & 1.6 & 8 & 1.6 & \multirow{3}{*}{$0.002 *$} \\
\hline & 5-15 minutes & 8 & 1.6 & 279 & 56.9 & 287 & 58.6 & \\
\hline & $>15$ minutes & 15 & 3.1 & 180 & 36.7 & 195 & 39.8 & \\
\hline \multirow{3}{*}{ Comfort in waiting area } & Good & 9 & 1.8 & 233 & 46.8 & 242 & 48.6 & \multirow{3}{*}{$<0.001^{*}$} \\
\hline & Satisfactory & 7 & 1.4 & 193 & 38.8 & 200 & 40.2 & \\
\hline & Poor & 9 & 1.8 & 47 & 9.4 & 56 & 11.2 & \\
\hline \multirow{3}{*}{ Rate hygiene in Clinic } & Poor & 0 & 0 & 5 & 1 & 5 & 1 & \multirow{3}{*}{0.09} \\
\hline & Satisfactory & 14 & 2.8 & 165 & 33.3 & 179 & 36.2 & \\
\hline & Good & 11 & 2.2 & 300 & 60.6 & 311 & 62.8 & \\
\hline \multirow{3}{*}{ Attitude of staff } & Good & 17 & 3.4 & 329 & 66.1 & 346 & 69.5 & \multirow{3}{*}{$<0.001 *$} \\
\hline & Satisfactory & 4 & 0.8 & 134 & 26.9 & 138 & 27.7 & \\
\hline & Poor & 4 & 0.8 & 10 & 2 & 14 & 2.8 & \\
\hline \multirow{2}{*}{ Dosage of medicine explained } & Yes & 17 & 3.7 & 409 & 89.3 & 426 & 93 & \multirow{2}{*}{$0.01 *$} \\
\hline & No & 5 & 1.1 & 27 & 5.9 & 32 & 7 & \\
\hline
\end{tabular}

Table 1: patient satisfaction and their associated factors at Sina Health, Education and welfare trust $(\mathrm{n}=557)$

\begin{tabular}{|l|c|c|l|c|}
\hline Variable & $\mathbf{p}$ value & Odds ratio & \multicolumn{2}{|c|}{$\mathbf{9 5 \%}$ confidence interval } \\
\hline & & & Lower & Upper \\
\hline Waiting time at pharmacy & 0.007 & 4.73 & 1.52 & 14.72 \\
\hline Assessing skills of doctor & 0.001 & & & \\
\hline Good & 0.006 & 0.051 & 0.006 & 0.434 \\
\hline Satisfactory & 0.072 & 0.072 & 0.017 & 0.301 \\
\hline Counseling skills of doctor & 0.007 & & & \\
\hline Good & 0.003 & 0.061 & 0.01 & 0.37 \\
\hline Satisfactory & 0.686 & 0.696 & 0.12 & 4.02 \\
\hline Listening skills of doctor & 0.01 & 6.44 & 1.52 & 12.18 \\
\hline
\end{tabular}

Table 2: Multivariable Logistic regression model of factors associated with patient satisfaction $(\mathrm{n}=557)$ 
different fields are invited to give pro bono lectures on family medicine topics relevant to Sina doctors' clinical practice. Doctors are assessed on best choice questions (BCQs) distributed after the sessions. Similarly, a two step medical audit is held for each doctor through audit of clinical notes, followed by onsite (consultation skills) audit. Performances are graded as excellent, satisfactory, unsatisfactory and poor. The frequency of the audit is based on grades awarded. For example, excellent audits are reaudited every 4 months whereas poor audits are reviewed every 2 weeks. The results of the CME post tests, medical audits and OSCE performances are tabulated and given due weightage in employee appraisal at the end of the year.

The pre-consultation time in this survey was 99 minutes. However the time the patient spent with the physician and his satisfaction with the doctor's consultation was found to be a stronger predictor of patient satisfaction than the amount of time spent waiting for the doctor. A previous study concluded that shortening patient waiting time at the expense of consultation time to improve patient satisfaction scores would not yield a positive outcome ${ }^{15}$. Yet, another study reported an inverse association between patient satisfaction and waiting time in ambulatory care settings ${ }^{16}$. Therefore, the excess waiting time should either be reduced or utilized by keeping patients engaged in health promotion, visual displays, hiring more volunteers for better crowd control and devising a mechanism that patients are not called for follow up visits unnecessarily.

Majority of the patients walked to the clinic and therefore the results show a relatively longer time to reach the clinic (22 minutes) which could be further reduced if patients took some type of transport to the service but that may not be cost effective.

Patients who perceived the attitude of the staff as "good" were more likely to be satisfied with services, as shown in a previous study which revealed that attitude of the paramedical staff and interpersonal aspects of healthcare are one of the key issues for patients determining quality of service ${ }^{17}$.

The socio-demographic profile has been shown to have an influence over the satisfaction levels of patients in previous studies ${ }^{18}$. Although we found that gender had no influence on patient satisfaction, but the percentage of males utilizing our services was $11 \%$ only. In developing countries, particularly for poor women, gender inequities in health services are common because health services are not available or acceptable to women ${ }^{19}$. Hence, a higher percentage of under privileged women visiting Sina PHC services is indeed very encouraging. As in previous studies, the clinic being close to home was shown to be associated with patient satisfaction $^{20}$, which is the probable reason for a greater utilization of these service by women.

Previous surveys have found that elderly patients are less likely to be satisfied with health care services, but in this survey only $2 \%$ of the patients were more than 60 years of age, and no association of age was observed with satisfaction $^{21}$.

Besides the factors mentioned, other important determinants of satisfaction are cost of services and medicines. More than $70 \%$ of the patients paid less than Rs 5 ( 5 cents) for services. This is because $81 \%$ patients at Sina are on Zakat (welfare) accounts. It can be also be deduced reasonably that the expectations of this group will be less than the community with higher education and socioeconomic status, hence the higher patient satisfaction rate ${ }^{22}$.

Although, this study is a part of regular audit of services by Sina, yet there are certain limitations of this study. The staff and doctors were aware of the survey, therefore there is a probability of hawthorne effect which may have resulted in modified behavior and hence a greater patient satisfaction. Moreover, a validated questionnaire for this survey would have improved the generalizability of results, which is another limitation of this study.

\section{CONCLUSION:}

Through this survey, a detailed insight was gained into the level of patient satisfaction with low cost primary healthcare services at Sina and factors associated with it. The results would encourage non-governmental organizations offering low cost PHC services to conduct patient satisfaction surveys and also to upgrade the quality of their services through lessons learnt from our organization, which is one of the largest, welfare NGO (Non-government organization) offering PHC services in Pakistan.

\section{REFERENCES:}

1. World Health Organization. The Declaration of Alma-Ata: The International Conference on Primary healthcare, AlmaAta, USSR, 6-12 September 1978.

2. Sabzwari SR. The case for family medicine in Pakistan. Journal of Pakistan Medical Association. 2015; 65: 660-661.

3. Rehman A, Shaikh BT, Ronis KA. Health care seeking patterns and out of pocket payments for children under five years of age living in Katchi Abadis (slums), in Islamabad, Pakistan. International journal for equity in health. 2014;13:30.

4. Ministry of Finance. Economic Survey of Pakistan 2013-14.

5. Siddiqi S, Haq I, Ghaffar A, Akhtar T, Mahaini R. Pakistan's maternal and child health policy: analysis, lessons and the way forward. Health Policy. 2004;69(1):117-30.

6. Shaikh BT. Private sector in health care delivery: A reality and a challenge in Pakistan. Journal of Ayub Medical College Abbottabad. 2015;27(2):496-8

7. Lucas JA. The satisfaction survey that matters. American Journal of Obstetrics and Gynecology. 2012;206(6):518-22.

8. McKinley R, Roberts C. Patient satisfaction with out of hours primary medical care. Quality in Health Care. 2001;10(1):238.

9. Lipp MJ, Riolo C, Riolo M, Farkas J, Liu T, Cisneros GJ. Showing you care: An empathetic approach to doctor-patient 
communication. Seminars in Orthodontics..2016; 22 (2): 8894

10. Al-Doghaither AH, Saeed AA. Consumers' satisfaction with primary health services in the city of Jeddah, Saudi Arabia. Saudi Medical Journal. 2000;21(5):447-54.

11. Bensing JM, Deveugele M, Moretti F, Fletcher I, van Vliet $\mathrm{L}$, Van Bogaert M, et al. How to make the medical consultation more successful from a patient's perspective? Tips for doctors and patients from lay people in the United Kingdom, Italy, Belgium and the Netherlands. Patient education and counseling. 2011;84(3):287-93.

12. Naidu A. Factors affecting patient satisfaction and healthcare quality. International Journal of Health Care Quality Assurance. 2009;22(4):366-81.

13. Paddison CA, Abel GA, Roland MO, Elliott MN, Lyratzopoulos G, Campbell JL. Drivers of overall satisfaction with primary care: evidence from the English General Practice Patient Survey. Health Expect. 2015;18(5):1081-92.

14. Frostholm L, Fink P, Oernboel E, Christensen KS, Toft T, Olesen F, et al. The uncertain consultation and patient satisfaction: the impact of patients' illness perceptions and a randomized controlled trial on the training of physicians' communication skills. Psychosomatic medicine. 2005;67(6):897-905.

15. Anderson RT, Camacho FT, Balkrishnan R. Willing to wait?: the influence of patient wait time on satisfaction with primary care. BMC Health Services Research. 2007;7(1):1
16. Michael M, Schaffer SD, Egan PL, Little BB, Pritchard PS. Improving wait times and patient satisfaction in primary care. Journal for Healthcare Quality.2013;35(2):50-60).

17. Tajeu, G. S., A. L. Cherrington, et al. "I'll get to you when we get to you": Exploring potential contributions of health care staff behaviors to patient perceptions of discrimination and satisfaction. American Journal of Public Health. $2015 ; 105(10)$.

18. Collins RL, Haas A, Haviland AM, Elliott MN. What Matters Most to Whom: Racial, Ethnic, and Language Differences in the Health Care Experiences Most Important to Patients. Med Care. 2017; 55(11):940-947.

19. Peters DH, Garg A, Bloom G, Walker DG, Brieger WR, Hafizur Rahman M. Poverty and access to health care in developing countries. Annals of the New York Academy of Sciences. 2008; 1136(1):161-71.

20. Fan VS, Burman M, McDonell MB, Fihn SD. Continuity of care and other determinants of patient satisfaction with primary care. Journal of General Internal Medicine. 2005;20(3):22633.

21. The World Book of Family Medicine - European Edition 2015. Assessing Patient Satisfaction in Primary Health Care - Reliable Information and Benchmarking.

22. Thoits PA. Stress and health major findings and policy implications. Journal of Health and Social Behavior. 2010;51:S41-S53. 